\title{
Ultraviolet Radiation-Induced Skin Aging: The Role of DNA Damage and Oxidative Stress in Epidermal Stem Cell Damage Mediated Skin Aging
}

\author{
Uraiwan Panich, Gunya Sittithumcharee, Natwarath Rathviboon, \\ and Siwanon Jirawatnotai
}

Laboratory for Systems Pharmacology, Department of Pharmacology, Faculty of Medicine Siriraj Hospital, Mahidol University, Bangkok 10700, Thailand

Correspondence should be addressed to Siwanon Jirawatnotai; siwanon.jir@mahidol.ac.th

Received 1 December 2015; Accepted 14 March 2016

Academic Editor: Hung-Fat Tse

Copyright (C) 2016 Uraiwan Panich et al. This is an open access article distributed under the Creative Commons Attribution License, which permits unrestricted use, distribution, and reproduction in any medium, provided the original work is properly cited.

\begin{abstract}
Skin is the largest human organ. Skin continually reconstructs itself to ensure its viability, integrity, and ability to provide protection for the body. Some areas of skin are continuously exposed to a variety of environmental stressors that can inflict direct and indirect damage to skin cell DNA. Skin homeostasis is maintained by mesenchymal stem cells in inner layer dermis and epidermal stem cells (ESCs) in the outer layer epidermis. Reduction of skin stem cell number and function has been linked to impaired skin homeostasis (e.g., skin premature aging and skin cancers). Skin stem cells, with self-renewal capability and multipotency, are frequently affected by environment. Ultraviolet radiation (UVR), a major cause of stem cell DNA damage, can contribute to depletion of stem cells (ESCs and mesenchymal stem cells) and damage of stem cell niche, eventually leading to photoinduced skin aging. In this review, we discuss the role of UV-induced DNA damage and oxidative stress in the skin stem cell aging in order to gain insights into the pathogenesis and develop a way to reduce photoaging of skin cells.
\end{abstract}

\section{Introduction}

Skin serves as the major protective organ of the body. This protection can be compromised by aging of the skin, a condition normally associated with skin inflammation, impaired wound repair, and increased risk of skin cancers $[1,2]$. Skin aging is defined as a continuous loss of certain characteristics present in juvenile skin, including decreased skin elasticity and pigmentation, and loss of ESCs [3-5]. Skin aging is a multifactorial process that involves genetic and environmental factors. A variety of environmental stresses, particularly UV light, can damage sun-exposed areas of the skin, such as the face and neck, and accelerate premature aging [6]. Skin aging that is associated with UVR exposure is referred to as photoaging.

Adult tissues, including skin epidermis, gastrointestinal epithelium, and the hematopoietic system, have a high rate of cell turnover. To maintain their functions and integrity, the physiological process of maintaining tissue homeostasis is attributed to a constant number of cells in renewing organs. ESCs are essential for the maintenance and regeneration of skin tissues [7].

Adult skin is composed of a diverse organized array of cells emanating from different embryonic origins. During development, skin is derived from embryonic origins of cell types from different germ layers. Epidermis and dermis are developed from ectoderm and mesoderm, respectively. The epidermis develops from embryonic surface ectoderm, which starts as a single layer of unspecified progenitor cells covering the embryo after neurulation and becomes the epidermal basal layer [8]. The epidermal basal layer is enriched with ESCs. Thus, cells in this layer give rise to all epidermal structures, including a stratified epidermis (also called interfollicular epidermis) and epidermal appendages, such as hair follicles, sebaceous glands, and sweat glands. The underlying dermis is derived primarily from mesoderm under the ectoderm. The mesoderm is the major source of mesenchymal stem cells that give rise to collagen-producing 
fibroblasts (a component of blood vessels that provide nutrients to skin), subcutaneous adipocytes, and immune cells in the skin.

Dermal fibroblasts are the main mesenchymal cell type in dermis. Substructurally, they were shown to be derived from the upper dermis and lower dermis. The fibroblasts from the former contribute to hair follicle formation, while the fibroblasts from the later produce fibril extracellular matrix (ECM). ECM from dermal fibroblasts plays a crucial role in structural integrity and repair of the skin and wound healing [9].

Skin is also populated by specialized cells, including melanocytes and sensory nerve endings of the skin that are derived from neural crest cells. Overall, approximately 20 different cell types reside within the skin $[8,10]$.

ESCs are defined by their ability to self-renew and differentiate into different cell lineages belonging to the skin [11]. ESCs are capable of differentiating into the entire set of cells that comprise the skin. Thus, the epidermis is used for skin graft to replace damaged or missing skin [12]. ESCs were shown to be able to develop into three distinct layers of epidermis: spinous layer, granular layer, and cornified layer (or stratum corneum, composed of dead, flattened, and anucleated cells). ESCs were also shown to be capable of differentiating into multiple skin cell lineages, including mature and specialized keratinocytes, sebocytes, or pigmented melanocytes $[13,14]$.

In addition to the interfollicular stem cell, ESCs include stem cells in hair follicles, the hair follicle stem cells (HFSCs) that reconstitute hair follicles, and play role in wound healing [15]. Another type of stem cells in the epidermis is melanocyte stem cells (MSCs), which are intermingled with HFSCs in the hair bulge. MSCs generate mature melanocytes that produce melanin, which absorbs ultraviolet (UV) light to prevent DNA damage and gives skin and hair their distinctive colors [16].

Microenvironment within skin is important for maintenance of stem cells. The microenvironment provided from the complex structure of ECM and basement membrane form integral stem cell niches for the ESCs [17]. Adult ESCs residing within the niches remain there for self-renewal, whereas their progeny, committed to differentiation, leave the basal call layer and migrate towards the epidermal surface [13]. This made it relatively useful to track each lineage along the steps of differentiation. Thus, skin has served as one of the ideal models for studying stem cell differentiation and the interaction between stem cells and their respective microenvironments [18].

Because of their exposure to DNA damaging conditions, skin stem cells are innately highly resistant to the aging process and DNA damage and carry highly active DNA repair mechanisms [19-21]. Nevertheless, ESCs can be impaired in advanced age [22] and are vulnerable to repetitive exposure to UVR [23-25]. If not repaired properly, damaged DNA may result in mutation or chromosomal rearrangements, which negatively influences self-renewal and potency of stem cells and promotes skin aging and/or cancer formation [26].

To prevent photoaging and skin cancers, reduced exposure to DNA damaging agent (UVR) and well-controlled
DNA repair mechanisms in ESCs are required to prevent photoaging and DNA damage-associated skin diseases, such as cutaneous basal cell and squamous cell carcinoma (BCCs and SCCs) [27].

While the role of UVR-induced DNA damage and oxidative stress in the skin aging involving ESC changes will be the focus of this review, it should also be noted that other factors may also contribute to this process. Skin in the area not normally exposed to UVR also can exhibit aging phenotype. Factors such as chronological shortening of skin cell telomere [28], increased inflammatory responses, and accumulation of senescent cells could contribute to skin aging by impairing stem cell function and homeostasis [29].

\section{UV-Induced DNA Damage in Skin Cells}

Repetitive exposure to solar UVR is among the principal environmental factors that can hasten the aging process of the skin, accompanied by progressive impairment of epidermal stem cell function [30]. UVR is a natural component of sunlight and is invisible to human eye. Three types of UV are categorized according to their wavelength: UV-A (315$400 \mathrm{~nm}), \mathrm{UV}-\mathrm{B}(280-315 \mathrm{~nm})$, and UV-C (100-280 nm). UV$\mathrm{C}$ is completely filtered out by the ozone layer of the Earth's stratosphere. Only UV-A and UV-B can reach the earth surface. However, climate change and depletion of the ozone layer may lead to increases in UV radiation at ground-level. UVR is known to be a mutagen; long-term overexposure to sunlight is associated with photoaging and formation of skin cancers [31]. Interestingly, both photoaging and cancerinducing effects of UVR are mediated through UVR's direct and indirect toxicity to the DNA [32].

The direct effect of UV irradiation occurs when DNA absorbs photons from UV-B. This results in structural rearrangement of nucleotides that then leads to defects in the DNA strand. Cyclobutane pyrimidine dimers (CPD) and pyrimidine (6-4) pyrimidone (6-4 photoproducts, 6-4 PPs) are the major products of UV-B-induced DNA damage [32]. Direct absorption of UV-B photons induces cycloaddition between $\mathrm{C} 5-\mathrm{C} 6$ of two adjacent pyrimidine bases and changes them into CPD. Meanwhile, covalent bond formation of C6-C4 of two adjacent pyrimidine bases generates 6-4 PPs photoproduct, which further converts to its Dewar valence isomer upon UV excitation at $314 \mathrm{~nm}$. The hotspot within these UV-induced DNA lesions is where tandem pyrimidine residues form (TT, TC, CT, and CC) [33]. At this point, cells will respond by promptly halting cell division to prevent further DNA damage and allow the DNA repair mechanism to start. In lower species, photolyase enzyme is employed to repair DNA by removal of UV-induced DNA lesions in a specific manner. The enzyme binds CPD or 6-4 PPs at lesion sites and splits the dimers back to undamaged bases. However, human and other mammalian cells no longer possess this enzyme. The main UV-induced DNA damage response in humans is the nucleotide excision repair (NER) pathway. There are 9 major proteins that function as NER in mammalian cells. RAD23s, RPA, ERCC1 proteins, and others also participate in nucleotide excision repair $[34,35]$. 
Deficiencies of these proteins lead to diseases associated with DNA damage and premature skin aging [36].

NER starts when XPC forms complex with CETN2 and RAD23 at distorted DNA sites and DNA is unwound by XPB. The damaged DNA is then stabilized by XPA, XPB, XPD, and RPA (single-stranded DNA binding proteins). RPA will then activate structure-specific endonucleases that contain XPG and ERCC1-XPF, followed by base excisions. Gaps are filled by DNA polymerase and fragments are sealed by DNA ligase. In addition to DNA repair pathway defects, mutations are also caused by error-prone DNA polymerase, which tends to add a residue at the position where the specific base is missing, thus creating "UV signature" mutations of $\mathrm{C} \rightarrow \mathrm{T}$ and $\mathrm{CC} \rightarrow \mathrm{TT}$ transition, as a result of UV irradiation [37].

UV radiation also indirectly damages DNA. Absorption of UV-A photons drives electrons and energy transfer from cellular photosensitizers, such as porphyrins, bilirubin, melanin, and pterins, to oxygen molecules creating the radical singlet oxygen $\left({ }^{1} \mathrm{O}_{2}\right)$ anion [32]. Consequently, the singlet oxygen anion induces guanine moiety oxidation followed by structural rearrangement and 8-oxo-7,8-dihydroguanine (8oxo-G) and 8-oxo-7,8-dihydro- $2^{\prime}$-deoxyguanosine (8-oxodG) formation, which is the biochemical marker of UVA-induced DNA damage. 8-oxo-G and 8-oxo-dG tend to pair with adenine instead of cytosine leading to C-T transition mutation $[38,39]$. Protective mechanisms against UV-induced oxidative damage acquire both antioxidative pathway and base excision repair (BER) pathway. Removal of 8-oxo-dG by BER is performed by a key enzyme, human 8-oxoguanine DNA glycosylase (hOGG1), which specifically recognizes and cleaves glycosidic bond from the DNA strand creating abasic (AP) sites. Subsequently, missing nucleotides are restored by DNA polymerase and gaps are sealed by DNA ligase. Accordingly, depletion of hOGG1 by microRNA inhibits the repair of UV-A-induced 8-oxo-dG in keratinocyte $\mathrm{HaCaT}$ cells [40].

\section{UV-Induced Depletion of Skin Stem Cells: A Multipronged Attack on Skin Stem Cells}

Several studies have investigated the role of DNA damage on function and genetic instability of ESCs [27, 41, 42]. Human ESCs are sensitive to DNA damaged lesions. Ionizing radiation-mediated DNA damage reduced colony-forming potential and viability of skin stem cells and destabilized the stem cell microenvironment in the bulge region of hair follicles. As a consequence, MSCs aging with related hair graying was observed [43]. It was shown that damage to ESC DNA by low-dose ionizing radiation significantly induced DSBsmediated chromatin modifications and that DSBs may also be passed on to their differentiated cell lineages [44]. Persistent exposure to UVR also increased DNA damaged lesions and mutations and led to premature aging or carcinogenesis of the skin [45].

Links between UVR exposure and skin aging can be observed when the DNA repair mechanism becomes dysfunctional. Quite often, defects in DNA repair systems of stem cells accelerate the accumulation of genome instability in lineage-primed progenitor cells during aging [46]. As described previously, NER is one of the most versatile DNA repair systems for eliminating a variety of helix-distorting DNA lesions induced by UVR [47]. Aberrance in this pathway contributes to UV hypersensitivity.

Mouse models genetically engineered to contain null allele of XPC shared skin aging phenotypes [48]. Genetic correction of keratinocyte SCs from NER-deficient XPC patients was observed to restore DNA repair capacity and cell survival following UVR, as well as providing long-term growth potential of stem cells [49]. Studies of human genetic disorders collectively known as progeroid syndromes (PS) (characterized by conditions that resemble premature aging) found mutations in the germ cell line or stem cells of genes in DNA repair pathways. PS-associated premature aging affects all tissues, including the skin, causing skin atrophy, hair graying, and abnormal pigmentation [36]. Patients with PS also develop other systemic diseases such as atherosclerosis, osteoporosis, and diabetes mellitus at an early age [50]. Some DNA repair defects implicated in PS are found in Werner's syndrome (WS), Hutchinson-Gilford progeria syndrome (HGPS), dyskeratosis congenita, xeroderma pigmentosum (XP), and Cockayne syndrome (CS) [51, 52]. All of these rare syndromes associate with depletion and dysfunction of adult stem cells and their progenies in various tissues, including the skin. The most well-studied inherited disorder, among these, is XP, involving the mutation of XPs genes and defective NER. $\mathrm{XP}$ patients, whose genome harbors XPs gene mutations, are generally hypersensitive to solar UVR, accumulate increased level of mutations, and develop skin aging and skin carcinoma by an early age with an approximate 1,000-fold increased risk $[53,54]$.

In addition, evidence of NER role in skin aging is observed in physiological aging. Decline in NER function associated with increasing age is speculated to contribute to the onset of aging manifested in various tissues including the skin.

Telomeres are nucleoprotein complexes that cap and save the ends of chromosomes from degradation and abnormal recombination. Telomeres shorten with each cell division and progressive telomere shortening ultimately results in cellular senescence. It is thus suggested that telomere dysfunction in association with p53-dependent premature cell senescence is possibly responsible for the aging of human stem cells.

Telomere shortening and dysfunction are a cause of genomic instability in WS (classic premature aging), resulting from a mutation in a gene coding the RecQ helicase WRN required for telomere maintenance during DNA replication [55].

Previous studies in the role of telomeres in epidermal stem cells observed that deletion of protein binding to telomeric DNA adversely affects skin homeostasis and development at embryonic stages in association with enhanced DNA damage response [56]. In addition, decline in function of ESCs was observed in association with shortened telomeres, which reduced proliferative potential in response to stimuli that may be implicated in the premature skin aging phenotype observed in mice [57]. Conversely, ESCs from aged skin were found to contain elevated levels of chromatin rearrangements 
and epigenetic changes and indicated that aging might be largely the attribution of structural changes to chromatin, potentially leading to epigenetically induced transcriptional deregulation [58]. Finally, a connection between UVR and telomere attrition has recently been emphasized. A report by Stout and Blasco showed that telomere length is, at least partly, maintained by the same NER pathway that protects DNA from UVR damage. UVR treatment on mouse $X P C^{-/-}$ epidermis resulted in telomere shortening in stem cells [59].

Taken together, these results argue for a strong connection between skin photoaging and DNA damage-induced stem cell exhaustion (Figure 1).

\section{ESC Exhaustion as a Consequence of Cell Cycle Checkpoint Activation}

DNA damage normally triggers activation of checkpoint pathways, simultaneously with the activation of DNA repair mechanisms. Checkpoint proteins such as p53 and ATM are activated upon UVR exposure and they elicit cell cycle arrest signaling to allow proper DNA repair [60]. Deficiencies in the checkpoint pathways result in accumulation of DNA damage lesions, resembling the phenotypes of DNA repair deficiencies. Protein product of ataxia-telangiectasia mutated (ATM) gene, a checkpoint protein that acts as a detecting sensor for DNA damage in a cell, triggers cell cycle arrest/DNA repair. Mutations of the ATM gene cause ataxia telangiectasia (AT), an inherited disease associated with premature aging, particularly at the skin. Although not a bona fide DNA repair gene, defects in ATM lead to accumulation of genomic damage and premature exhaustion of the stem cell pool in various tissues, including the skin [46].

A gene downstream of ATM, p53, is a transcription factor, which primarily functions as a gatekeeper for DNA mutations [61]. Timely expression of wild-type $p 53$ is crucial in preventing deregulated or stressed cells from turning into cancer cells [62]. p53 does this by transactivating expressions of gene sets that initiate cell cycle arrest, DNA repair, senescence, or apoptosis. Examples of genes activated by $p 53$ include $X P E / D D B 2$ (a gene in the NER pathway) [63], p21 (a cell cycle inhibitor), BCL2-associated X protein $(B A X)$, and TNF receptor subfamily, member 6 (FAS) (both proapoptotic proteins). [64-66]. Upon UV irradiation, p53 is phosphorylated by several kinases, namely, ATM, ATR (ATM-related kinase), and CHK1/2. UV-induced phosphorylation at Serine 15 increased $p 53$ stability and protein level that associated with DNA damage [61]. Inhibition of p53 phosphorylation during UV-induced DNA damage increased sensitivity to UV-induced skin tumor development [67], indicating that p53 activation after DNA damage effectively halts the expansion of cells with damaged DNA, in order to prevent cancer formation.

Interestingly, overactivation or prolonged activation of checkpoint proteins will also result in the diminishing of selfrenewal potential of ESCs. Skin of the mouse lacking the negative regulatory protein of $p 53, M D M 2$, elicited increased basal p53 level and premature aging skin phenotypes, including thinning of the epidermis, reduced wound healing, and progressive hair loss [68].
In agreement with the negative role of prolonged $p 53$ expression on stem cell potency, it was shown that p53 restricted the stem cell gene expression program [69]. Suppression of $p 53$ by viral protein or siRNA facilitated reprograming of iPS $[70,71]$. In vivo, $p 53^{-/-}$mice showed marked stem cell expansion and were prone to teratoma [72]. Lastly, UV-damaged DNA binding proteins 1 (DDB1) and 2 (DDB2) cooperate with $p 53$ in DNA damage response. Deletion of $D D B 1$ in mouse resulted in genomic instability and loss of epidermis, which could be partially rescued by deletion of p53 [73]. Deletion of DDB2, another gene regulated by $p 53$, resulted in UV-induced skin cancer [74].

p63, a p53-related gene, is well accepted as a protein that maintains ESCs. Expression of $p 63$ selectively distributed in the basal cells of both stratified and glandular epithelia, both of which contained ESCs, suggested its critical role in the regulation of stemness. $p 63$ and its isoforms are regarded as a marker of ESCs [75]. The transactivating isoform of p63 (TAp63) functions to suppress hyperproliferation of skin stem/progenitor cells that result in exhaustion of the ESC pool or DNA damage. TAp63-null mouse skin demonstrates cells with terminal cell cycle arrest (senescence) phenotypes and premature skin aging [76]. Since $p 63$ was shown to respond to stress signals, similar to $p 53$, and is upregulated in prolonged cultured cells, it might be reasonable to expect that $p 63$ works in DNA damage response and contributes to mediating UV-induced ESC exhaustion [77]. However, there is still no evidence to support this notion.

Checkpoint proteins also triggered DNA repair. In addition to those already mentioned, a mouse model for BRCA1 deficiency emphasized the significance of unrepaired DNA in stem cell depletion. Deficiency of BRCA1, a central protein in single-stranded and double-stranded DNA repair in epidermis is associated with increased DNA damage, genome instability, loss of hair follicle stem cells (HFSCs), and hair follicles. Defects appeared to be the result of activated $p 53$, since deletion of $p 53$ offset the effects of BRCA1 loss [78]. $B R C A 1$ plays a role in UV-induced DNA damage response. $\mathrm{UV}$-induced DNA damage produced $B R C A 1$-positive foci as part of the damage response [79]. Interestingly, $B R C A 1$ deletion in skin epidermis using K14-Cre did not affect stem cells in sebaceous grand and interfollicular epidermis, suggesting that BRCA1 is only indispensable for some populations of stem cells.

\section{DNA Damage Promotes Photoaging by Depriving Stem Cells of Their Niche}

Maintenance and repair of many adult tissues rely on stem cells to produce numerous differentiated cells that replace or repair the tissue [80-82]. Stem cells in the pool spend relatively long period of time in a quiescent state and the pool is to be used throughout the life of the organism. ESCs in the pool will exit from the quiescent stage to divide to produce more stem cells or committed progeny cells, which will then eventually differentiate into various cellular components of skin. Maintenance of the pool relies on extrinsic factors, such as signaling from neighboring cells and 


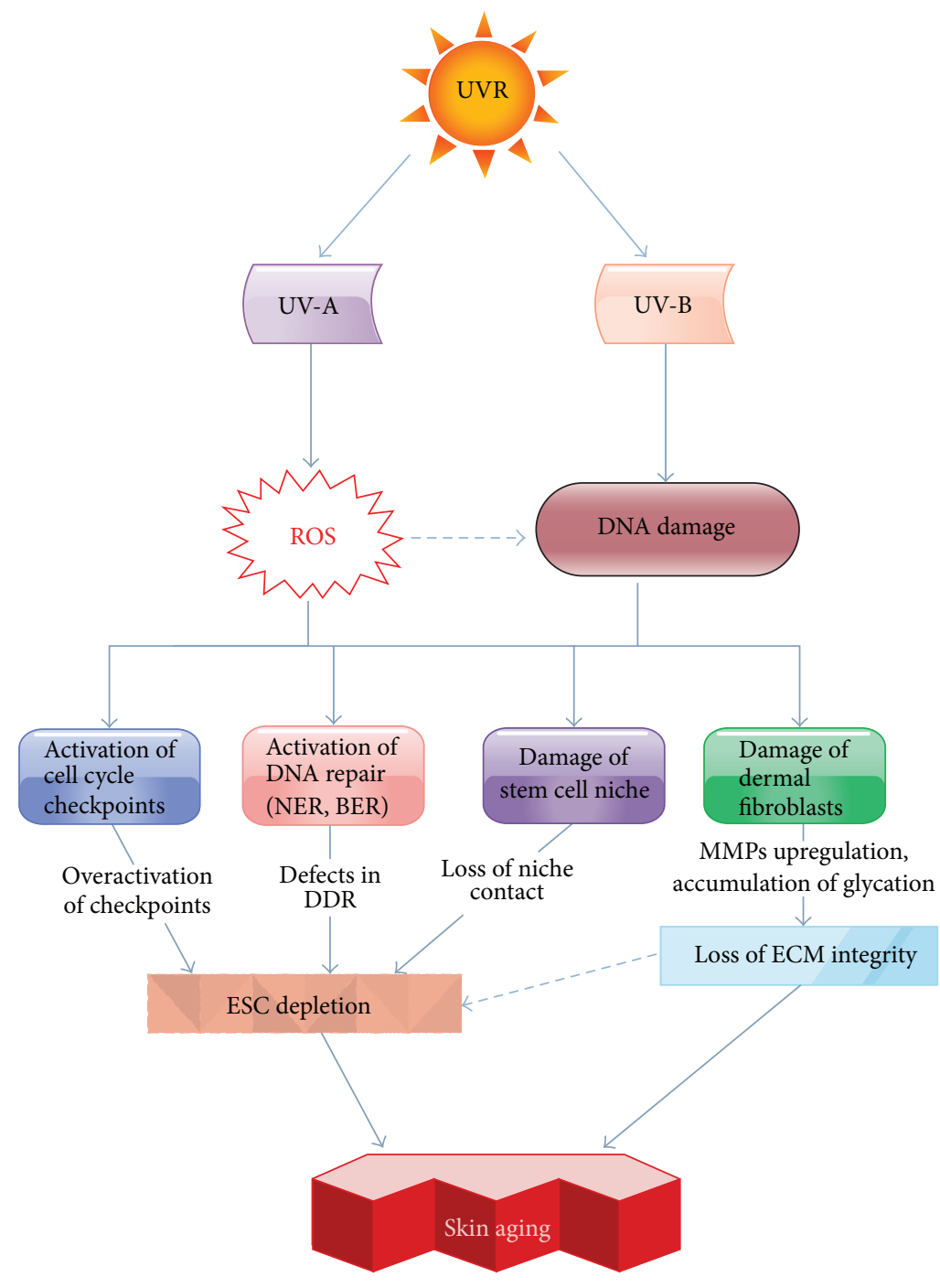

FIGURE 1: Skin aging induced by UVR-induced DNA damage to ESCs. UVR is the major skin stressor capable of damaging ESC DNA (UV-B) or promoting production of the DNA toxic ROS (UV-A). DNA damaging effects of UVR result in activation of cell cycle arrest (checkpoint activation) and DNA repair proteins, damaged stem cell niche, and dermal fibroblasts. These facilitate ESC depletion and loss of extracellular matrix (ECM) integrity, leading to premature skin aging.

surrounding environment (microenvironment) that make up the stem cell niche and cell autonomous regulations [80, 83]. Irradiated quiescent MSCs prematurely differentiate in the niche upon their activation without sufficiently renewing themselves. These data suggest that tissue radiosensitivity may be dependent on the state of somatic stem cells in their local microenvironment [84].

UV-induced DNA damage was also reported to interfere with skin stem cell pool by causing changes in the stem cell niche. ESCs are surrounded and maintained by a microenvironment of various cell types and substances [85]. The homeostasis of stem cells is influenced by cross talk between ESCs and mesenchyme cells and the interaction between stem cells and extracellular matrix (ECM; laminin, type IV collagen, nidogen, and perlecan), the constituents of the basement membrane of skin. Communication between
ECM components is mediated by integrins, a family of transmembrane proteins on the ESCs surface. Integrins contact other cells or the ECM. Such connections trigger signal transduction pathways, which result in biological responses, such as cell proliferation or cell motility. The notion that ESCs express abundant levels of integrins indicates that communication with the niche environment is fundamental to ESC stemness (high level of $\alpha 6$-integrin is considered one of the hallmarks of ESCs). Fibronectin, vitronectin, collagen, and laminin are all ligands for integrins and have been reported to play an intricate role in ESC homeostasis. It was demonstrated in a study of HFSCs that the mesenchymal niche of the hair follicle provides molecular signals that are sufficient to induce hair growth [86]. Interaction between integrins and ECM is required for stem cell maintenance. Loss of contact from the ECM decreases potency of stem cells 
[87] and $\beta 1$ integrin-mediated adhesion signaling is essential for epidermal progenitor cell expansion.

DNA damage appears to also activate expression of genes that are not directly implicated in DNA damage response but that play a role in skin stem cell homeostasis. Transcription factor c-Myc is one of the genes found to be activated by UVR. $c-M y c$ overexpression was detected approximately 5 hours after UV irradiation of the skin cells [88]. $c-M y c$ expression was shown to correlate with reduced potency of skin cells. Deregulated $c-M y c$ expression was shown to deplete ESCs by making the ESCs overproliferate, move out of their niche, and then differentiate $[89,90] . c-M y c$ could also induce ESC differentiation as mediated by $c-M y c$ in the $c-M y c-M i z 1$ complex, which supposedly suppresses genes critical for skin cell stemness [91]. In fact, $\beta 1$ integrin was reported to be a gene target for repression by the c-Myc-Mizl complex in stem cell depleted skin [91]. These results indicated that stem cells favor low level of $\mathrm{c}-\mathrm{Myc}$ to stay in undifferentiated status, with DNA damage triggering untimely $c-M y c$ overexpression, resulting in ESC exhaustion.

In addition, long-term UVR exposure can cause restructuring of the extracellular matrix. Proteins in extracellular matrix components contain UV-absorbing chromophores, which are vulnerable to the UV-induced structural changes [92]. UV-induced changes in ECM are well characterized. UVR exposure not only upregulates the expression of $M M P-1$, $M M P-2, M M P-3, M M P-7, M M P-9$, and $M M P-12$ [93], but also promotes a prooxidative environment in human skin, by which the structure of the skin will be further damaged. Although this restructuring of the extracellular matrix likely disturbs the ESC pool, detailed studies are needed to identify and elucidate the effects.

\section{UV-Induced Oxidative Stress:

A Major Assault on Skin and a Potential
Preventive and Therapeutic Target for
Antioxidants in Skin Photoaging

UV-A-induced ROS is, to a major degree, responsible for ESCs DNA damage. Normally, reactive oxygen species (ROS) are endogenously produced in the cell from various metabolic processes, including cellular respiration, which takes place in mitochondria and is the primary source of intracellular ROS [94]. However, ROS production can also be a by-product of cell exposure to the environment, including exposure to UVR, ionizing radiation, pollutants, cigarette smoke, alcohol, heavy or transition metals, and certain drugs [95-97]. ROS include not only free radicals, such as superoxide anion radical $\left(\mathrm{O}_{2}{ }^{--}\right)$and hydroxyl radical $\left(\mathrm{OH}^{*}\right)$, but also nonradicals like singlet oxygen $\left({ }^{1} \mathrm{O}_{2}\right)$ and hydrogen peroxide $\left(\mathrm{H}_{2} \mathrm{O}_{2}\right)$. ROS play a dual role as both harmful and useful molecules in the cell; as such, an appropriate level of ROS is needed for normal physiological function of mammalian cells and, therefore, is essential for life. Phagocytic ROS act as weapons for the immune system to kill pathogenic microorganisms that cause infection. ROS also take physiological roles in the regulation of several cellular functions and signaling cascades involved in proliferation, differentiation, and survival of various types of cells, such as endothelial cells, fibroblasts, smooth muscle cells, cardiac myocytes, neuronal cells, and skin keratinocytes [98-101].

While ESCs appear capable of adequate responsiveness to changes in their environment, accumulated oxidative damage to biomolecules in the cells, including lipids, proteins, and DNA, caused by repetitive exposure to environmental insults, in particular UVR, may compromise their selfrenewal capacity and promote loss of ESC numbers, resulting in premature aging $[42,102]$. Although the mechanisms by which ROS act on molecular changes in ESCs in the process of skin aging are not well understood, it has been shown that elevated ROS is responsible for premature aging of the stem cells of the skin. Wang et al. observed that persistent elevation of ROS and oxidative DNA damage are associated with increased senescence and decreased clonogenic capacity of hematopoietic stem cells (HSC) [103].

Thus, it is very important to understand the role of ROS in ESC DNA damage and disturbed ESC homeostasis, in particular, in association with DNA damage. In many cases, the models that contained defect in antioxidation pathways or DNA repair helped to explain the significance of ROSinduced DNA damage during ESC exhaustion process.

\section{ROS in DNA Damage and Defective DNA Repair Systems Implicated in Loss of Epidermal Stemness}

Beyond DNA repair mechanisms, protection of skin cells against UV-induced DNA damage includes enzymatic antioxidants [104]. It has been suggested that stem cell DNA damage is often accompanied by oxidative stress, which is an accountable factor for stem cell senescence and aging [105, 106]. Excessive ROS can result in single-strand break products. Oxidative DNA damage is continuously accumulated throughout the lifespan of a living cell. During physiological aging, DNA is constantly exposed to intracellular ROS, as by-products of metabolic process. ROS can introduce DNA base or sugar damage resulting in formation of approximately 5000 single-strand breaks in each cell in the human body daily $[107,108]$.

ROS similarly damage both nuclear and mitochondrial DNA (mtDNA). It was recently reported that aging of the skin was observed to be associated with mtDNA damage and mutations. mtDNA mutations were suggested as being a sensitive biomarker of UVR exposure and oxidative stress in human skin [109]. Additionally, our study previously demonstrated that induction of oxidative DNA damage and defects in DNA repair hOGG1 that could be responsible for photocarcinogenesis were associated with patients with BCC [110]. Another report showed that overproduction of ROS (generated during ionizing radiation) was involved with MSC depletion in graying hair, an obvious sign of aging. Detailed study showed that ROS-induced DNA damage led to MSC attrition and discontinued renewal of MSCs in mice by enhancing MSC differentiation into mature melanocytes. The same study proposed that ATM was the sensor of ROS-induced DNA damage and acted as a checkpoint for 
the stemness. Deficiency of ATM from MSCs stimulated MSC differentiation [111]. In another study, ROS-induced depletion of HSC was shown to be mediated by p38 MAPK phosphorylation in the $A T M^{-/-}$cells [112].

Integrity of chromosomes is determined by the length of the telomere. Cellular aging is associated with shortened telomere. Adequate telomerase (TERT) activity is required to maintain telomere length. DNA damage in association with telomere dysfunction and shortening precipitates premature aging and shortened lifespan, leading to depletion of almost all tissue stem cell reserves and dysfunction of stem cells, including self-renewal and repair capacity of ESCs and melanocytes of the follicle during the hair growth process $[113,114]$. Interestingly, high telomerase expression, which is associated with long telomeres, is commonly found in adult stem/progenitor cell compartments, including the stem cells in hair follicles, whereas low telomerase expression has been detected in human fibroblasts and epithelial cells $[115,116]$.

ROS may also activate the p53-p21 axis, Akt-MAPK, ATM pathways [117], and forkhead homeobox type O (FOXO) transcription factors in various types of stem cells by influencing telomere length [118]. Moreover, the reduced proliferative potency of stem cells was induced by ROS-activating p53 stabilization [119]. Skin aging associated with ROS accumulation, thus, was found to be rescued in the skin of lategeneration p53 knockout mice [120]. In these mice, there were improved wound healing, hair growth, and skin renewal to levels comparable to those of wild-type mice, as well as increased ESC numbers and improved mobilization capacity [120].

Effects of ROS on supportive cell types have also been studied. Exposure of human skin fibroblasts, an important cellular component of skin microenvironment, to UVR has been shown to result in oxidative stress and enhanced expression of cell cycle inhibitors p16INK4A and p53/p21WAF1/ CIP1. Upregulations were predictably followed by premature senescence of fibroblasts [121, 122], which unavoidably disturbed stem cell-niche cross talk [123]. High level of ROS was also reported to induce skin fibroblasts to secrete high levels of matrix metalloproteinases (MMPs), which caused extensive ECM remodeling in dermal layers [124-126].

In addition to the direct DNA damage caused by UVR, ROS, a by-product of UV-A exposure, also plays prominent role as a DNA damaging agent that damages DNA in an equally extensive manner. However, due to the transient nature of ROS, it is possible to ameliorate its effect and protect the skin from premature aging. Pharmacologically, ROS has been considered as a potential target for photoaging prevention and therapies.

\section{Preventive and Therapeutic Implications of Antioxidants in Photoaging through Preservation of Stemness}

Regarding the importance of stem cells, several protective mechanisms have been detected in different stem cell types for protecting against ROS and UV-induced DNA damage $[127,128]$.
At present, strategies to potentiate DNA repair pathway or to restore functions of defective NER proteins are under investigation. Gene therapies for the XP might be possible with the emergence of gene editing technologies $[129,130]$.

Currently, prevention and treatment strategies for photoaged skin mostly center on strengthening antioxidant defense for the cells. Mammalian tissues are equipped with an array of nonenzymatic and enzymatic antioxidant systems that work in a complex network to maintain the optimal level of ROS in the cells or a redox balance by several mechanisms. These mechanisms work to neutralize oxidants, inhibit oxidative damage, and regulate transcription factors involved in redox and scavenging reactions [131]. Proliferation and differentiation of human cells underlie a delicate control of several signaling pathways [132]. The balance of redox homeostasis and regulation of ROS-mediated signaling are part of the central regulation involved in self-renewal, proliferation, and differentiation of normal stem and progenitor cells in human tissues, including the skin [133].

Since skin cells can be exposed to environmental sources of ROS, particularly UVR, endogenous antioxidants function as a crucial defense system to preserve redox balance required for regulation of epidermal homeostasis and prevent ROSinduced skin damage [134]. Important endogenous antioxidants include enzymatic antioxidants, such as superoxide dismutase (SOD), catalase (CAT), glutathione peroxidase (GPx), glutathione reductase, and thioredoxin reductase, and nonenzymatic antioxidants or low molecular weight antioxidants, such as ascorbate or vitamin C, glutathione (GSH), and $\alpha$-tocopherol or vitamin E [135]. SOD is an important antioxidant enzyme that converts $\mathrm{O}_{2}{ }^{\circ-}$ into $\mathrm{H}_{2} \mathrm{O}_{2}$, which is finally degraded into water by CAT and GPx.

However, when generated in excess, ROS promote oxidative stress that can damage cellular structures and biomolecules, including lipids, proteins, and DNA, as well as interfering with normal signaling cascades. It has been proposed that an imbalance between ROS production and antioxidant defense would occur as a consequence of overwhelming ROS production and the substantial reduction in antioxidant levels that occurs with advanced aging $[136,137]$. On the other hand, the effect of excessive ROS on total lifespan was implicated in a study, which showed that whole body deletion of the SOD1 gene caused a reduced lifespan in mice that died by "aging dead," suggesting that the physiological level of SOD1 is required to prevent premature aging [138]. Mitochondrial ROS has also been suggested to be a driving force of accelerated aging caused by ROS damage in adult stem cells [139]. Lastly, oxidative stress may also have an impact on the aging process by causing biochemical and physiological changes that accelerate age-related diseases [140].

ROS may be the leading cause of physiological change in skin stem cells. It has been proposed that the maintenance of self-renewal and differentiation capacity of ESCs into old age and their resistance to cellular aging may be attributed to their ability to control levels of intracellular ROS by antioxidant defenses. Consistent with this theory, prevention of oxidative stress, thus, is the key to prevent stem cell exhaustion in the skin [141]. In nature, SOD may be an important antioxidant 


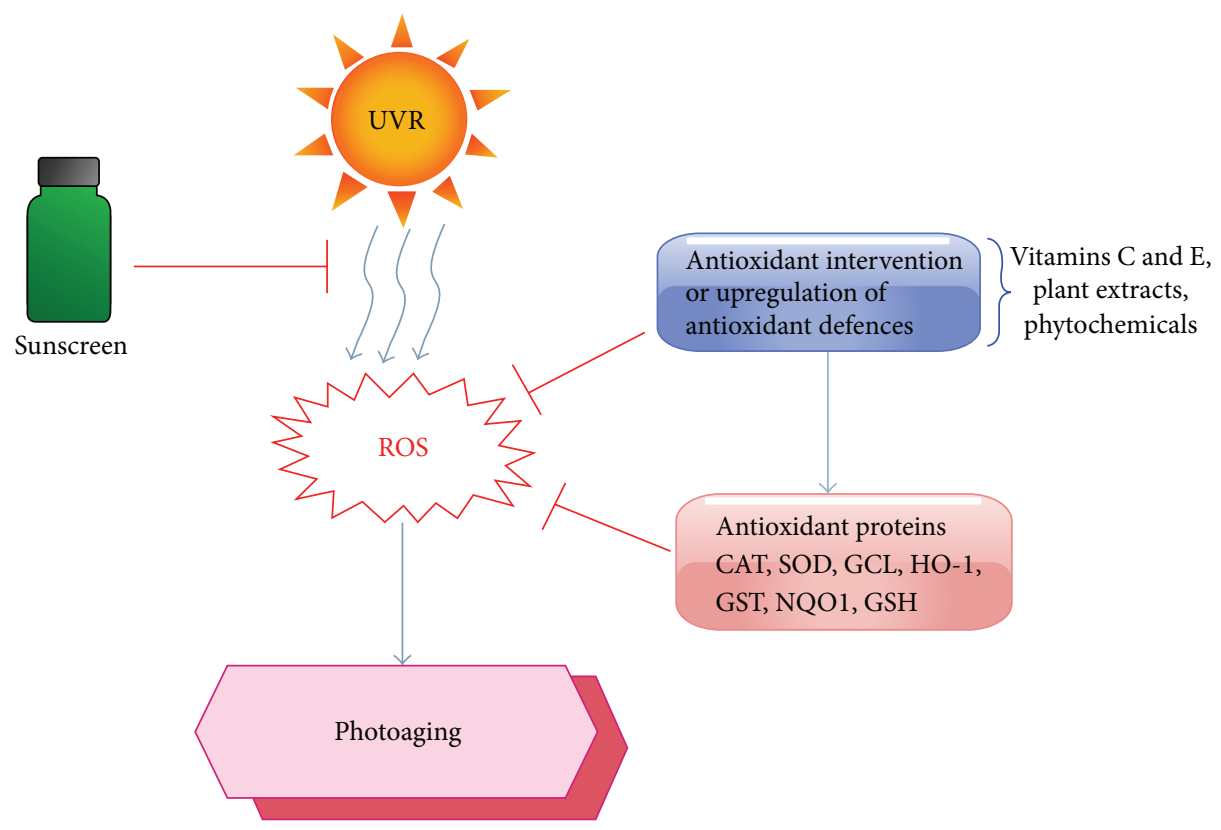

FIgure 2: Anti-ROS as a potential anti-skin aging intervention. Possible interventions that delay ESC DNA damage, by preventing UVR exposure using sunscreen, anti-ROS, or upregulation of antioxidant proteins.

enzyme that is responsible for the tolerance of ESCs to ROSmediated aging process, because the SOD gene was observed to be highly expressed in ESCs isolated from both young adult mice and old adult mice and its expression remained unchanged in the ESCs from old mice [20].

Stem cells undergo a self-renewal process that produces low levels of intracellular ROS as by-products. Although these ROS are endogenous and low in amount, they are still harmful to stem cells. In order to maintain redox homeostasis, antioxidant defense systems are transcriptionally upregulated in response to ROS formation. As such, attempts have been made to explore the role of transcription factors that can serve as redox regulators in the self-renewal of stem cells, in particular, FOXO family and nuclear factor erythroid-2related factor 2 (Nrf2) [142]. Activated FOXOs translocate into the nucleus and mediate transcription of target antioxidant genes, including CAT and SOD [143]. Disruption of FOXO proteins, which are key downstream components of the $\mathrm{PI}(3) \mathrm{K}$ pathway, was associated with depletion of tissue stem cells without external stimulation $[144,145]$.

Nrf2 has been widely accepted as the key regulator of redox homeostatic genes involved in human skin adaption to oxidative stress, which can stimulate its translocation into the nucleus to bind to the antioxidant response element (ARE), a cis-acting enhancer sequence in the region of several genes encoding antioxidant/detoxification enzymes, including glutamate cysteine ligase (GCL), heme oxygenase1 (HO-1), glutathione transferase (GST), and $\mathrm{NAD}(\mathrm{P}) \mathrm{H}$ quinine oxidoreductase-1 (NQO1) [146-148]. Depletion of Nrf2 can compromise the abilities of various cells (such as mouse embryonic and human primary skin fibroblasts and keratinocyte $\mathrm{HaCaT}$ cells) to protect against photooxidative damage [149-152]. Moreover, Nrf2, which may be a target of keratinocyte growth factor, was observed to play a role in cutaneous wound repair in mice in association with an increase in mRNA expressions of collagen and VEGF (vascular endothelial growth factor), a main regulator of angiogenesis [153]. UV-B-induced apoptosis of basal keratinocytes in murine epidermis was blocked by suprabasal keratinocytes capable of controlling their survival through Nrf2-regulated antioxidant defenses including GSH [154].

While melanin and enzymatic antioxidants serve as endogenous defense of the skin against UVR, accumulative exposure to UVR can overwhelm the ROS defense mechanism. Exogenous and dietary antioxidants such as vitamin $\mathrm{C}$ (ascorbic acid), vitamin E ( $\alpha$-tocopherol), beta-carotenes, and different phytochemicals, particularly polyphenols derived from plants-based food and beverages, as well as herbal products that play a crucial role in maintaining redox homeostasis and antioxidant intervention are thus proposed as being useful in delaying skin photoaging and helping to prevent skin cancer $[104,155]$ (Figure 2).

As UV-mediated oxidative stress can adversely affect ESCs, enhancing capacity of cellular antioxidant defenses to counteract oxidative stress would represent a promising strategy for inhibition of photoaged skin. A number of studies using skin cell culture reconstructed skin and animal models have reported protective roles of natural and synthetic antioxidants, as well as medicinal plants against UV-mediated skin photoaging through modulation of antioxidant defense system. For example, compounds capable of activating Nrf2 were able to prevent UV-B-dependent cell death in primary keratinocytes [156] and tanshinones derived from medicinal plant S. miltiorrhiza, which acted as Nrf2 inducer, suppressed 
UV-induced damage of human skin cells, and reconstructed human skin through upregulation of Nrf2 and its target antioxidants including GCL and NQO1 [157]. Purified T. parthenium extracts inhibited UV-mediated DNA damage through activation of Nrf2-ARE signaling in primary human keratinocytes [158]. Eckstolonol isolated from E. cava was shown to protect keratinocyte $\mathrm{HaCaT}$ cells against UV-Bmediated photooxidative stress, cytotoxicity, and DNA damage possibly through induction of CAT and SOD activities [159]. 18 $\beta$-glycyrrhetinic acid, the major active ingredient in licorice root, inhibited UV-induced skin photoaging in a mouse model by induction in skin collagen content and downregulation of MMP-1 and MMP-3 associated with increased activities of SOD and GPx [160]. Furthermore, the mechanisms by which oral administration of Polypodium leucotomos delayed skin tumor development in hairless mice might involve improvement in antioxidant defense status [161]. K. parviflora (black ginger) extracts orally administrated to hairless mice exerted antiphotoaging effects on UV-B-irradiated hairless mice by suppression of MMPs and upregulation of collagen genes in association with induction of CAT expression [162]. We have also reported the protective roles of antioxidant phytochemicals, such as caffeic acid, ferulic acid, and gallic acid, which are ubiquitously present in plants-based food and beverages, against UV-A-induced melanogenesis in different melanoma cell lines and MMP-1 upregulation in $\mathrm{HaCaT}$ cells in association with promotion of Nrf2-related antioxidant defenses, including CAT and GSH antioxidant system (GST and GPx) at the cellular and molecular levels [163-166]. Nevertheless, few studies have addressed whether targeting ROS and antioxidant mechanisms could be a promising strategy for the delay of premature skin aging by promoting the capacity of skin stem cells for skin repair and rejuvenation.

Choi et al. suggested that redox status is essential for stemness in skin equivalents and demonstrated that vitamin C, plant extracts (G. lucidum and R. sachalinensis), and a novel tripeptide "ACQ: alanine-cysteine-glutamine" having high antioxidant activities promoted stemness and the proliferative capacity of epidermal basal cells by improving microenvironment through regulation of integrins, the main receptors for ECM $[167,168]$. In addition to various antioxidant compounds reported as having beneficial effects on stemness of the skin, the use of adult stem cells and their niches to contribute to regeneration and repair of damaged tissues has been proposed as a promising strategy in cell-based therapy in tissue injury. Mesenchymal stem cells within the stromal-vascular fraction of subcutaneous adipose tissue successfully employed to substitute dermal fibroblasts for skin construction were demonstrated to improve UV-Binduced wrinkles in hairless mice and exert antiapoptotic effects on dermal fibroblasts through antioxidant mechanisms, including upregulation of various antioxidant proteins $[3,169]$.

Notably, pharmacologic agents with antioxidant actions and tissue engineering approaches have been proposed to promote stemness of the skin, although their efficacy and safety for clinical application in prevention and treatment of skin photoaging warrant further investigation.

\section{Competing Interests}

The authors hereby declare no personal or professional competing interests regarding any aspect of this study.

\section{Acknowledgments}

This work was supported by Thailand Research Fund (RSA5580012 and RSA5580018), Siriraj Research Fund, Faculty of Medicine Siriraj Hospital, Mahidol University, and the Advanced Research on Pharmacology Fund, Siriraj Foundation (D003421). Uraiwan Panich and Siwanon Jirawatnotai were supported by a Chalermphrakiat Grant, Faculty of Medicine Siriraj Hospital, Mahidol University.

\section{References}

[1] D. A. Lewis, J. B. Travers, C. Machado, A.-K. Somani, and D. F. Spandau, "Reversing the aging stromal phenotype prevents carcinoma initiation," Aging, vol. 3, no. 4, pp. 407-416, 2011.

[2] G. B. Maru, K. Gandhi, A. Ramchandani, and G. Kumar, "The role of inflammation in skin cancer," Advances in Experimental Medicine and Biology, vol. 816, pp. 437-469, 2014.

[3] M. Mimeault and S. K. Batra, "Recent advances on skin-resident stem/progenitor cell functions in skin regeneration, aging and cancers and novel anti-aging and cancer therapies," Journal of Cellular and Molecular Medicine, vol. 14, no. 1-2, pp. 116-134, 2010.

[4] E. C. Naylor, R. E. B. Watson, and M. J. Sherratt, "Molecular aspects of skin ageing," Maturitas, vol. 69, no. 3, pp. 249-256, 2011.

[5] C. López-Otín, M. A. Blasco, L. Partridge, M. Serrano, and G. Kroemer, “The hallmarks of aging," Cell, vol. 153, no. 6, pp. 11941217, 2013.

[6] J. Wenk, P. Brenneisen, C. Meewes et al., "UV-induced oxidative stress and photoaging," Current Problems in Dermatology, vol. 29, pp. 83-94, 2001.

[7] P. A. Sotiropoulou and C. Blanpain, "Development and homeostasis of the skin epidermis," Cold Spring Harbor Perspectives in Biology, vol. 4, no. 7, Article ID a008383, 2012.

[8] S. Liu, H. Zhang, and E. Duan, "Epidermal development in mammals: key regulators, signals from beneath, and stem cells," International Journal of Molecular Sciences, vol. 14, no. 6, pp. 10869-10895, 2013.

[9] R. R. Driskell, B. M. Lichtenberger, E. Hoste et al., "Distinct fibroblast lineages determine dermal architecture in skin development and repair," Nature, vol. 504, no. 7479, pp. 277-281, 2013.

[10] C. Blanpain and E. Fuchs, "Epidermal stem cells of the skin," Annual Review of Cell and Developmental Biology, vol. 22, pp. 339-373, 2006.

[11] G. Mascré, S. Dekoninck, B. Drogat et al., "Distinct contribution of stem and progenitor cells to epidermal maintenance," Nature, vol. 489, no. 7415, pp. 257-262, 2012.

[12] L. Alonso and E. Fuchs, "Stem cells in the skin: waste not, Wnt not," Genes and Development, vol. 17, no. 10, pp. 1189-1200, 2003.

[13] C. Blanpain and E. Fuchs, "Epidermal homeostasis: a balancing act of stem cells in the skin," Nature Reviews Molecular Cell Biology, vol. 10, no. 3, pp. 207-217, 2009.

[14] I. L. Weissman, "Stem cells: units of development, units of regeneration, and units in evolution," Cell, vol. 100, no. 1, pp. 157-168, 2000. 
[15] L. Yang and R. Peng, "Unveiling hair follicle stem cells," Stem Cell Reviews and Reports, vol. 6, no. 4, pp. 658-664, 2010.

[16] Y.-C. Hsu, L. Li, and E. Fuchs, "Emerging interactions between skin stem cells and their niches," Nature Medicine, vol. 20, no. 8, pp. 847-856, 2014.

[17] K. A. Moore and I. R. Lemischka, "Stem cells and their niches," Science, vol. 311, no. 5769, pp. 1880-1885, 2006.

[18] C. Grillon, A. Matejuk, M. Nadim, N. Lamerant-Fayel, and C. Kieda, "News on microenvironmental physioxia to revisit skin cell targeting approaches," Experimental Dermatology, vol. 21, no. 10, pp. 723-729, 2012.

[19] D. Racila and J. R. Bickenbach, "Are epidermal stem cells unique with respect to aging?" Aging, vol. 1, no. 8, pp. 746-750, 2009.

[20] M. M. Stern and J. R. Bickenbach, "Epidermal stem cells are resistant to cellular aging," Aging Cell, vol. 6, no. 4, pp. 439-452, 2007.

[21] A. Giangreco, M. Qin, J. E. Pintar, and F. M. Watt, "Epidermal stem cells are retained in vivo throughout skin aging," Aging Cell, vol. 7, no. 2, pp. 250-259, 2008.

[22] A. Giangreco, S. J. Goldie, V. Failla, G. Saintigny, and F. M. Watt, "Human skin aging is associated with reduced expression of the stem cell markers $\beta 1$ integrin and MCSP," Journal of Investigative Dermatology, vol. 130, no. 2, pp. 604-608, 2010.

[23] E. Makrantonaki and C. C. Zouboulis, "William J. Cunliffe scientific awards. Characteristics and pathomechanisms of endogenously aged skin," Dermatology, vol. 214, no. 4, pp. 352360, 2007.

[24] S. Bosset, M. Bonnet-Duquennoy, P. Barré et al., "Photoageing shows histological features of chronic skin inflammation without clinical and molecular abnormalities," The British Journal of Dermatology, vol. 149, no. 4, pp. 826-835, 2003.

[25] P. Janich, K. Toufighi, G. Solanas et al., "Human epidermal stem cell function is regulated by circadian oscillations," Cell Stem Cell, vol. 13, no. 6, pp. 745-753, 2013.

[26] T. Sperka, J. Wang, and K. L. Rudolph, "DNA damage checkpoints in stem cells, ageing and cancer," Nature Reviews Molecular Cell Biology, vol. 13, no. 9, pp. 579-590, 2012.

[27] K. Rass and J. Reichrath, "UV damage and DNA repair in malignant melanoma and nonmelanoma skin cancer," Advances in Experimental Medicine and Biology, vol. 624, pp. 162-178, 2008.

[28] L. Liu and T. A. Rando, "Manifestations and mechanisms of stem cell aging," The Journal of Cell Biology, vol. 193, no. 2, pp. 257-266, 2011.

[29] J. Doles and W. M. Keyes, "Epidermal stem cells undergo ageassociated changes," Aging, vol. 5, no. 1, pp. 1-2, 2013.

[30] C. C. Zouboulis, J. Adjaye, H. Akamatsu, G. Moe-Behrens, and C. Niemann, "Human skin stem cells and the ageing process," Experimental Gerontology, vol. 43, no. 11, pp. 986-997, 2008.

[31] E. F. Bernstein, Yue Qiu Chen, J. B. Kopp et al., "Long-term sun exposure alters the collagen of the papillary dermis: comparison of sun-protected and photoaged skin by Northern analysis immunohistochemical staining, and confocal laser scanning microscopy," Journal of the American Academy of Dermatology, vol. 34, no. 2, part 1, pp. 209-218, 1996.

[32] J.-L. Ravanat, T. Douki, and J. Cadet, "Direct and indirect effects of UV radiation on DNA and its components," Journal of Photochemistry and Photobiology B: Biology, vol. 63, no. 1-3, pp. 88-102, 2001.

[33] P. J. Rochette, J.-P. Therrien, R. Drouin et al., "UVA-induced cyclobutane pyrimidine dimers form predominantly at thymine-thymine dipyrimidines and correlate with the mutation spectrum in rodent cells," Nucleic Acids Research, vol. 31, no. 11, pp. 2786-2794, 2003.

[34] I. Kamileri, I. Karakasilioti, and G. A. Garinis, "Nucleotide excision repair: new tricks with old bricks," Trends in Genetics, vol. 28, no. 11, pp. 566-573, 2012.

[35] W. L. de Laat, N. G. J. Jaspers, and J. H. J. Hoeijmakers, "Molecular mechanism of nucleotide excision repair," Genes \& Development, vol. 13, no. 7, pp. 768-785, 1999.

[36] Y. Kamenisch and M. Berneburg, "Progeroid syndromes and UV-induced oxidative DNA damage," The Journal of Investigative Dermatology, vol. 14, no. 1, pp. 8-14, 2009.

[37] D. E. Brash, J. A. Rudolph, J. A. Simon et al., "A role for sunlight in skin cancer: UV-induced p53 mutations in squamous cell carcinoma," Proceedings of the National Academy of Sciences of the United States of America, vol. 88, no. 22, pp. 10124-10128, 1991.

[38] A. Klungland, I. Rosewell, S. Hollenbach et al., "Accumulation of premutagenic DNA lesions in mice defective in removal of oxidative base damage," Proceedings of the National Academy of Sciences of the United States of America, vol. 96, no. 23, pp. 13300-13305, 1999.

[39] D. Thomas, A. D. Scot, R. Barbey, M. Padula, and S. Boiteux, "Inactivation of OGG1 increases the incidence of $\mathrm{G} \cdot \mathrm{C} \rightarrow \mathrm{T} \cdot \mathrm{A}$ transversions in Saccharomyces cerevisiae: evidence for endogenous oxidative damage to DNA in eukaryotic cells," Molecular \& General Genetics, vol. 254, no. 2, pp. 171-178, 1997.

[40] A. Javeri, J. G. Lyons, X. X. Huang, and G. M. Halliday, "Downregulation of Cockayne syndrome $\mathrm{B}$ protein reduces human 8-oxoguanine DNA glycosylase-1 expression and repair of UV radiation-induced 8-oxo-7,8-dihydro-2' -deoxyguanine," Cancer Science, vol. 102, no. 9, pp. 1651-1658, 2011.

[41] O. S. Kwon, H. G. Yoo, J. H. Han, S. R. Lee, J. H. Chung, and H. C. Eun, "Photoaging-associated changes in epidermal proliferative cell fractions in vivo," Archives of Dermatological Research, vol. 300, no. 1, pp. 47-52, 2008.

[42] M. Ruetze, K. Dunckelmann, A. Schade et al., "Damage at the root of cell renewal-UV sensitivity of human epidermal stem cells," Journal of Dermatological Science, vol. 64, no. 1, pp. 16-22, 2011.

[43] H. Aoki, A. Hara, T. Motohashi, and T. Kunisada, "Keratinocyte stem cells but not melanocyte stem cells are the primary target for radiation-induced hair graying," The Journal of Investigative Dermatology, vol. 133, no. 9, pp. 2143-2151, 2013.

[44] M. Sokolov and R. Neumann, "Effects of low doses of ionizing radiation exposures on stress-responsive gene expression in human embryonic stem cells," International Journal of Molecular Sciences, vol. 15, no. 1, pp. 588-604, 2014.

[45] F. Tsatsou, M. Trakatelli, A. Patsatsi, K. Kalokasidis, and D. Sotiriadis, "Extrinsic aging: UV-mediated skin carcinogenesis," Dermato-Endocrinology, vol. 4, no. 3, pp. 285-297, 2012.

[46] A. Behrens, J. M. van Deursen, K. L. Rudolph, and B. Schumacher, "Impact of genomic damage and ageing on stem cell function," Nature Cell Biology, vol. 16, no. 3, pp. 201-207, 2014.

[47] R. P. Rastogi, Richa, A. Kumar, M. B. Tyagi, and R. P. Sinha, "Molecular mechanisms of ultraviolet radiation-induced DNA damage and repair," Journal of Nucleic Acids, vol. 2010, Article ID 592980, 32 pages, 2010.

[48] M. Hosseini, W. Mahfouf, M. Serrano-Sanchez et al., "Premature skin aging features rescued by inhibition of NADPH oxidase activity in XPC-deficient mice," The Journal of Investigative Dermatology, vol. 135, no. 4, pp. 1108-1118, 2015. 
[49] E. Warrick, M. Garcia, C. Chagnoleau et al., "Preclinical corrective gene transfer in xeroderma pigmentosum human skin stem cells," Molecular Therapy, vol. 20, no. 4, pp. 798-807, 2012.

[50] N. E. Sharpless and R. A. DePinho, "How stem cells age and why this makes us grow old," Nature Reviews Molecular Cell Biology, vol. 8, no. 9, pp. 703-713, 2007.

[51] V. Bergoglio and T. Magnaldo, "Nucleotide excision repair and related human diseases," Genome Dynamics, vol. 1, pp. 35-52, 2006.

[52] T. Davis and D. Kipling, "Werner Syndrome as an example of inflamm-aging: possible therapeutic opportunities for a progeroid syndrome?" Rejuvenation Research, vol. 9, no. 3, pp. 402-407, 2006.

[53] J. E. Cleaver, E. T. Lam, and I. Revet, "Disorders of nucleotide excision repair: the genetic and molecular basis of heterogeneity," Nature Reviews Genetics, vol. 10, no. 11, pp. 756-768, 2009.

[54] K. H. Kraemer, M.-M. Lee, A. D. Andrews, and W. C. Lambert, "The role of sunlight and DNA repair in melanoma and nonmelanoma skin cancer: the xeroderma pigmentosum paradigm," Archives of Dermatology, vol. 130, no. 8, pp. 10181021, 1994.

[55] L. Crabbe, A. Jauch, C. M. Naeger, H. Holtgreve-Grez, and J. Karlseder, "Telomere dysfunction as a cause of genomic instability in Werner syndrome," Proceedings of the National Academy of Sciences of the United States of America, vol. 104, no. 7, pp. 2205-2210, 2007.

[56] P. Martínez, I. Ferrara-Romeo, J. M. Flores, and M. A. Blasco, "Essential role for the TRF2 telomere protein in adult skin homeostasis," Aging Cell, vol. 13, no. 4, pp. 656-668, 2014.

[57] I. Siegl-Cachedenier, I. Flores, P. Klatt, and M. A. Blasco, "Telomerase reverses epidermal hair follicle stem cell defects and loss of long-term survival associated with critically short telomeres," The Journal of Cell Biology, vol. 179, no. 2, pp. 277290, 2007.

[58] N. Schuler and C. E. Rübe, "Accumulation of DNA damageinduced chromatin alterations in tissue-specific stem cells: the driving force of aging?" PLoS ONE, vol. 8, no. 5, Article ID e63932, 2013.

[59] G. J. Stout and M. A. Blasco, "Telomere length and telomerase activity impact the UV sensitivity syndrome xeroderma pigmentosum C," Cancer Research, vol. 73, no. 6, pp. 1844-1854, 2013.

[60] A. L. Craig, J. Holcakova, L. E. Finlan et al., "DeltaNp63 transcriptionally regulates ATM to control p53 Serine-15 phosphorylation," Molecular Cancer, vol. 9, article 195, 2010.

[61] N. D. Lakin and S. P. Jackson, "Regulation of p53 in response to DNA damage," Oncogene, vol. 18, no. 53, pp. 7644-7655, 1999.

[62] C. Dai and W. Gu, "P53 post-translational modification: deregulated in tumorigenesis," Trends in Molecular Medicine, vol. 16, no. 11, pp. 528-536, 2010.

[63] G. Kulaksiz, J. T. Reardon, and A. Sancar, "Xeroderma pigmentosum complementation group $\mathrm{E}$ protein (XPE/DDB2): purification of various complexes of XPE and analyses of their damaged DNA binding and putative DNA repair properties," Molecular and Cellular Biology, vol. 25, no. 22, pp. 9784-9792, 2005.

[64] E. Oda, R. Ohki, H. Murasawa et al., "Noxa, a BH3-only member of the Bcl-2 family and candidate mediator of p53-induced apoptosis," Science, vol. 288, no. 5468, pp. 1053-1058, 2000.
[65] M. Müller, S. Wilder, D. Bannasch et al., "p53 activates the CD95 (APO-1/Fas) gene in response to DNA damage by anticancer drugs," The Journal of Experimental Medicine, vol. 188, no. 11, pp. 2033-2045, 1998.

[66] J. K. Sax, P. Fei, M. E. Murphy, E. Bernhard, S. J. Korsmeyer, and W. S. El-Deiry, "BID regulation by p53 contributes to chemosensitivity," Nature Cell Biology, vol. 4, no. 11, pp. 842849, 2002.

[67] W. Bruins, E. Zwart, L. D. Attardi et al., "Increased sensitivity to UV radiation in mice with a p53 point mutation at Ser389," Molecular and Cellular Biology, vol. 24, no. 20, pp. 8884-8894, 2004.

[68] H. S. Gannon, L. A. Donehower, S. Lyle, and S. N. Jones, "Mdm2-p53 signaling regulates epidermal stem cell senescence and premature aging phenotypes in mouse skin," Developmental Biology, vol. 353, no. 1, pp. 1-9, 2011.

[69] R. M. Marión, K. Strati, H. Li et al., "A p53-mediated DNA damage response limits reprogramming to ensure iPS cell genomic integrity," Nature, vol. 460, no. 7259, pp. 1149-1153, 2009.

[70] Y. Zhao, X. Yin, H. Qin et al., "Two supporting factors greatly improve the efficiency of human iPSC generation," Cell Stem Cell, vol. 3, no. 5, pp. 475-479, 2008.

[71] P. Mali, Z. Ye, H. H. Hommond et al., "Improved efficiency and pace of generating induced pluripotent stem cells from human adult and fetal fibroblasts," STEM CELLS, vol. 26, no. 8, pp. 1998-2005, 2008.

[72] M. Kanatsu-Shinohara, K. Inoue, J. Lee et al., "Generation of pluripotent stem cells from neonatal mouse testis," Cell, vol. 119, no. 7, pp. 1001-1012, 2004.

[73] Y. Cang, J. Zhang, S. A. Nicholas, A. L. Kim, P. Zhou, and S. P. Goff, "DDB1 is essential for genomic stability in developing epidermis," Proceedings of the National Academy of Sciences of the United States of America, vol. 104, no. 8, pp. 2733-2737, 2007.

[74] T. Yoon, A. Chakrabortty, R. Franks, T. Valli, H. Kiyokawa, and P. Raychaudhuri, "Tumor-prone phenotype of the DDB2deficient mice," Oncogene, vol. 24, no. 3, pp. 469-478, 2005.

[75] G. Melino, E. M. Memmi, P. G. Pelicci, and F. Bernassola, "Maintaining epithelial stemness with p63," Science Signaling, vol. 8, no. 387, p. re9, 2015.

[76] M. Senoo, F. Pinto, C. P. Crum, and F. McKeon, "p63 is essential for the proliferative potential of stem cells in stratified epithelia," Cell, vol. 129, no. 3, pp. 523-536, 2007.

[77] X. Su, M. Paris, Y. J. Gi et al., “TAp63 prevents premature aging by promoting adult stem cell maintenance," Cell Stem Cell, vol. 5, no. 1, pp. 64-75, 2009.

[78] P. A. Sotiropoulou, A. E. Karambelas, M. Debaugnies et al., "Brcal deficiency in skin epidermis leads to selective loss of hair follicle stem cells and their progeny," Genes and Development, vol. 27, no. 1, pp. 39-51, 2013.

[79] J. Dunn, M. Potter, A. Rees, and T. M. Rünger, "Activation of the Fanconi anemia/BRCA pathway and recombination repair in the cellular response to solar ultraviolet light," Cancer Research, vol. 66, no. 23, pp. 11140-11147, 2006.

[80] N. Li and H. Clevers, "Coexistence of quiescent and active adult stem cells in mammals," Science, vol. 327, no. 5965, pp. 542-545, 2010.

[81] K. W. Orford and D. T. Scadden, "Deconstructing stem cell self-renewal: genetic insights into cell-cycle regulation," Nature Reviews Genetics, vol. 9, no. 2, pp. 115-128, 2008. 
[82] B. D. Simons and H. Clevers, "Strategies for homeostatic stem cell self-renewal in adult tissues," Cell, vol. 145, no. 6, pp. 851862, 2011.

[83] S. J. Morrison and A. C. Spradling, "Stem cells and niches: mechanisms that promote stem cell maintenance throughout life," Cell, vol. 132, no. 4, pp. 598-611, 2008.

[84] M. Ueno, T. Aoto, Y. Mohri, H. Yokozeki, and E. K. Nishimura, "Coupling of the radiosensitivity of melanocyte stem cells to their dormancy during the hair cycle," Pigment Cell \& Melanoma Research, vol. 27, no. 4, pp. 540-551, 2014.

[85] S. Özbek, P. G. Balasubramanian, R. Chiquet-Ehrismann, R. P. Tucker, and J. C. Adams, "The evolution of extracellular matrix," Molecular Biology of the Cell, vol. 21, no. 24, pp. 4300-4305, 2010.

[86] V. Greco, T. Chen, M. Rendl et al., "A two-step mechanism for stem cell activation during hair regeneration," Cell Stem Cell, vol. 4, no. 2, pp. 155-169, 2009.

[87] A. Piwko-Czuchra, H. Koegel, H. Meyer et al., " $\beta 1$ integrinmediated adhesion signalling is essential for epidermal progenitor cell expansion," PLoS ONE, vol. 4, no. 5, Article ID e5488, 2009.

[88] S. Takahashi, A. D. Pearse, and R. Marks, "The acute effects of ultraviolet-B radiation on c-myc and c-Ha ras expression in normal human epidermis," Journal of Dermatological Science, vol. 6, no. 2, pp. 165-171, 1993.

[89] R. L. Waikel, Y. Kawachi, P. A. Waikel, X.-J. Wang, and D. R. Roop, "Deregulated expression of c-Myc depletes epidermal stem cells," Nature Genetics, vol. 28, no. 2, pp. 165-168, 2001.

[90] A. Gandarillas and F. M. Watt, "c-Myc promotes differentiation of human epidermal stem cells," Genes \& Development, vol. 11, no. 21, pp. 2869-2882, 1997.

[91] A. Gebhardt, M. Frye, S. Herold et al., "Myc regulates keratinocyte adhesion and differentiation via complex formation with Mizl," The Journal of Cell Biology, vol. 172, no. 1, pp. 139149, 2006.

[92] M. J. Sherratt, C. P. Bayley, S. M. Reilly, N. K. Gibbs, C. E. M. Griffiths, and R. E. B. Watson, "Low-dose ultraviolet radiation selectively degrades chromophore-rich extracellular matrix components," The Journal of Pathology, vol. 222, no. 1, pp. 32-40, 2010.

[93] R. E. B. Watson, N. K. Gibbs, C. E. M. Griffiths, and M. J. Sherratt, "Damage to skin extracellular matrix induced by UV exposure," Antioxidants \& Redox Signaling, vol. 21, no. 7, pp. 1063-1077, 2014.

[94] B. Chance, H. Sies, and A. Boveris, "Hydroperoxide metabolism in mammalian organs," Physiological Reviews, vol. 59, no. 3, pp. 527-605, 1979.

[95] J. E. Klaunig, Z. Wang, X. Pu, and S. Zhou, "Oxidative stress and oxidative damage in chemical carcinogenesis," Toxicology and Applied Pharmacology, vol. 254, no. 2, pp. 86-99, 2011.

[96] J. Huang, M. Okuka, M. McLean, D. L. Keefe, and L. Liu, "Telomere susceptibility to cigarette smoke-induced oxidative damage and chromosomal instability of mouse embryos in vitro," Free Radical Biology and Medicine, vol. 48, no. 12, pp. 1663-1676, 2010.

[97] B. Poljšak and R. Fink, "The protective role of antioxidants in the defence against ROS/RNS-mediated environmental pollution," Oxidative Medicine and Cellular Longevity, vol. 2014, Article ID 671539, 22 pages, 2014.

[98] D. G. Nicholls and S. L. Budd, "Mitochondria and neuronal survival," Physiological Reviews, vol. 80, no. 1, pp. 315-360, 2000.
[99] C. Caliceti, P. Nigro, P. Rizzo, and R. Ferrari, "ROS, Notch, and Wnt signaling pathways: crosstalk between three major regulators of cardiovascular biology," BioMed Research International, vol. 2014, Article ID 318714, 8 pages, 2014.

[100] B. Su, S. Mitra, H. Gregg et al., "Redox regulation of vascular smooth muscle cell differentiation," Circulation Research, vol. 89, no. 1, pp. 39-46, 2001.

[101] A. Van Laethem, K. Nys, S. Van Kelst et al., "Apoptosis signal regulating kinase-1 connects reactive oxygen species to p38 MAPK-induced mitochondrial apoptosis in UVB-irradiated human keratinocytes," Free Radical Biology \& Medicine, vol. 41, no. 9, pp. 1361-1371, 2006.

[102] Q. Shen, H. Jin, and X. Wang, "Epidermal stem cells and their epigenetic regulation," International Journal of Molecular Sciences, vol. 14, no. 9, pp. 17861-17880, 2013.

[103] Y. Wang, L. Liu, S. K. Pazhanisamy, H. Li, A. Meng, and D. Zhou, "Total body irradiation causes residual bone marrow injury by induction of persistent oxidative stress in murine hematopoietic stem cells," Free Radical Biology \& Medicine, vol. 48, no. 2, pp. 348-356, 2010.

[104] A. Godic, B. Poljšak, M. Adamic, and R. Dahmane, "The role of antioxidants in skin cancer prevention and treatment," Oxidative Medicine and Cellular Longevity, vol. 2014, Article ID 860479, 6 pages, 2014.

[105] R. A. J. Signer and S. J. Morrison, "Mechanisms that regulate stem cell aging and life span," Cell Stem Cell, vol. 12, no. 2, pp. 152-165, 2013.

[106] A. A. Moskalev, M. V. Shaposhnikov, E. N. Plyusnina et al., "The role of DNA damage and repair in aging through the prism of Koch-like criteria," Ageing Research Reviews, vol. 12, no. 2, pp. 661-684, 2013.

[107] M. M. Vilenchik and A. G. Knudson, "Endogenous DNA double-strand breaks: Production, fidelity of repair, and induction of cancer," Proceedings of the National Academy of Sciences of the United States of America, vol. 100, no. 22, pp. 12871-12876, 2003.

[108] J. H. J. Hoeijmakers, "DNA damage, aging, and cancer," New England Journal of Medicine, vol. 361, no. 15, pp. 1475-1485, 2009.

[109] M. A. Birch-Machin, E. V. Russell, and J. A. Latimer, "Mitochondrial DNA damage as a biomarker for ultraviolet radiation exposure and oxidative stress," The British Journal of Dermatology, vol. 169, supplement 2, pp. 9-14, 2013.

[110] L. Chaisiriwong, R. Wanitphakdeedecha, P. Sitthinamsuwan et al., "A case-control study of involvement of oxidative DNA damage and alteration of antioxidant defense system in patients with basal cell carcinoma: modulation by tumor removal," Oxidative Medicine and Cellular Longevity, vol. 2016, Article ID 5934024, 12 pages, 2016.

[111] K. Inomata, T. Aoto, N. T. Binh et al., "Genotoxic stress abrogates renewal of melanocyte stem cells by triggering their differentiation," Cell, vol. 137, no. 6, pp. 1088-1099, 2009.

[112] K. Ito, A. Hirao, F. Arai et al., "Reactive oxygen species act through p38 MAPK to limit the lifespan of hematopoietic stem cells," Nature Medicine, vol. 12, no. 4, pp. 446-451, 2006.

[113] E. Sahin and R. A. Depinho, "Linking functional decline of telomeres, mitochondria and stem cells during ageing," Nature, vol. 464, no. 7288, pp. 520-528, 2010.

[114] I. Flores, M. L. Cayuela, and M. A. Blasco, "Effects of telomerase and telomere length on epidermal stem cell behavior," Science, vol. 309, no. 5738, pp. 1253-1256, 2005. 
[115] S. Y. Rha, E. Izbicka, R. Lawrence et al., "Effect of telomere and telomerase interactive agents on human tumor and normal cell lines," Clinical Cancer Research, vol. 6, no. 3, pp. 987-993, 2000.

[116] W. C. Hahn, C. M. Counter, A. S. Lundberg, R. L. Beijersbergen, M. W. Brooks, and R. A. Weinberg, "Creation of human tumour cells with defined genetic elements," Nature, vol. 400, no. 6743, pp. 464-468, 1999.

[117] Y. Peng, M. Xuan, V. Y. L. Leung, and B. Cheng, "Stem cells and aberrant signaling of molecular systems in skin aging," Ageing Research Reviews, vol. 19, pp. 8-21, 2015.

[118] Z. Tothova, R. Kollipara, B. J. Huntly et al., "FoxOs are critical mediators of hematopoietic stem cell resistance to physiologic oxidative stress," Cell, vol. 128, no. 2, pp. 325-339, 2007.

[119] C. Richardson, S. Yan, and C. G. Vestal, "Oxidative stress, bone marrow failure, and genome instability in hematopoietic stem cells," International Journal of Molecular Sciences, vol. 16, no. 2, pp. 2366-2385, 2015.

[120] I. Flores and M. A. Blasco, "A p53-dependent response limits epidermal stem cell functionality and organismal size in mice with short telomeres," PLoS ONE, vol. 4, no. 3, Article ID e4934, 2009.

[121] W. Chen, J. Kang, J. Xia et al., "p53-related apoptosis resistance and tumor suppression activity in UVB-induced premature senescent human skin fibroblasts," International Journal of Molecular Medicine, vol. 21, no. 5, pp. 645-653, 2008.

[122] D. Volonte, Z. Liu, P. M. Musille et al., "Inhibition of nuclear factor-erythroid 2-related factor (Nrf2) by caveolin-1 promotes stress-induced premature senescence," Molecular Biology of the Cell, vol. 24, no. 12, pp. 1852-1862, 2013.

[123] V. Pekovic and C. J. Hutchison, "Adult stem cell maintenance and tissue regeneration in the ageing context: the role for a-type lamins as intrinsic modulators of ageing in adult stem cells and their niches," Journal of Anatomy, vol. 213, no. 1, pp. 5-25, 2008.

[124] N. Philips, T. Keller, C. Hendrix et al., "Regulation of the extracellular matrix remodeling by lutein in dermal fibroblasts, melanoma cells, and ultraviolet radiation exposed fibroblasts," Archives of Dermatological Research, vol. 299, no. 8, pp. 373-379, 2007.

[125] J. Varani, M. K. Dame, L. Rittie et al., "Decreased collagen production in chronologically aged skin: roles of age-dependent alteration in fibroblast function and defective mechanical stimulation," The American Journal of Pathology, vol. 168, no. 6, pp. 1861-1868, 2006.

[126] T. Quan and G. J. Fisher, "Role of age-associated alterations of the dermal extracellular matrix microenvironment in human skin aging," Gerontology, vol. 61, no. 5, pp. 427-434, 2015.

[127] M. Orciani, S. Gorbi, M. Benedetti et al., "Oxidative stress defense in human-skin-derived mesenchymal stem cells versus human keratinocytes: different mechanisms of protection and cell selection," Free Radical Biology and Medicine, vol. 49, no. 5, pp. 830-838, 2010.

[128] S. Maynard, A. M. Swistowska, J. W. Lee et al., "Human embryonic stem cells have enhanced repair of multiple forms of DNA damage," STEM CELLS, vol. 26, no. 9, pp. 2266-2274, 2008.

[129] A. Dupuy, J. Valton, S. Leduc, J. Armier, R. Galetto, and A. Gouble, "Targeted gene therapy of xeroderma pigmentosum cells using meganuclease and TALEN ${ }^{\mathrm{TM}}$," PLOS ONE, vol. 8, no. 11, Article ID e78678, 2013.

[130] E. Warrick, M. Garcia, and C. Chagnoleau, "preclinical corrective gene transfer in xeroderma pigmentosum human skin stem cells," Molecular Therapy, vol. 20, no. 4, pp. 798-807, 2012.
[131] J. M. Wood and K. U. Schallreuter, "A plaidoyer for cutaneous enzymology: our view of some important unanswered questions on the contributions of selected key enzymes to epidermal homeostasis," Experimental Dermatology, vol. 17, no. 7, pp. 569578, 2008.

[132] J. Kenyon and S. L. Gerson, "The role of DNA damage repair in aging of adult stem cells," Nucleic Acids Research, vol. 35, no. 22, pp. 7557-7565, 2007.

[133] R. Mouzannar, J. McCafferty, G. Benedetto, and C. Richardson, "Transcriptional and phospho-proteomic screens reveal stem cell activation of insulin-resistance and transformation pathways following a single minimally toxic episode of Ros," International Journal of Genomics and Proteomics, vol. 2, no. 1, pp. 34-49, 2011.

[134] U. Wölfle, G. Seelinger, G. Bauer, M. C. Meinke, J. Lademann, and C. M. Schempp, "Reactive molecule species and antioxidative mechanisms in normal skin and skin aging," Skin Pharmacology and Physiology, vol. 27, no. 6, pp. 316-332, 2014.

[135] S. R. Pinnell, "Cutaneous photodamage, oxidative stress, and topical antioxidant protection," Journal of the American Academy of Dermatology, vol. 48, no. 1, pp. 1-22, 2003.

[136] R. Kohen, "Skin antioxidants: their role in aging and in oxidative stress-new approaches for their evaluation," Biomedicine \& Pharmacotherapy, vol. 53, no. 4, pp. 181-192, 1999.

[137] H.-L. Hu, R. J. Forsey, T. J. Blades, M. E. J. Barratt, P. Parmar, and J. R. Powell, "Antioxidants may contribute in the fight against ageing: an in vitro model," Mechanisms of Ageing and Development, vol. 121, no. 1-3, pp. 217-230, 2001.

[138] V. I. Pérez, A. Bokov, H. Van Remmen et al., "Is the oxidative stress theory of aging dead?" Biochimica et Biophysica ActaGeneral Subjects, vol. 1790, no. 10, pp. 1005-1014, 2009.

[139] S. K. George, Y. Jiao, C. E. Bishop, and B. Lu, "Mitochondrial peptidase IMMP2L mutation causes early onset of ageassociated disorders and impairs adult stem cell self-renewal," Aging Cell, vol. 10, no. 4, pp. 584-594, 2011.

[140] Y. H. Edrey and A. B. Salmon, "Revisiting an age-old question regarding oxidative stress," Free Radical Biology \& Medicine, vol. 71, pp. 368-378, 2014.

[141] L. B. Boyette and R. S. Tuan, "Adult stem cells and diseases of aging," Journal of Clinical Medicine, vol. 3, no. 1, pp. 88-134, 2014.

[142] K. Wang, T. Zhang, Q. Dong, E. C. Nice, C. Huang, and Y. Wei, "Redox homeostasis: the linchpin in stem cell self-renewal and differentiation," Cell Death \& Disease, vol. 4, article e537, 2013.

[143] L. O. Klotz, C. Sánchez-Ramos, I. Prieto-Arroyo, P. Urbánek, H. Steinbrenner, and M. Monsalve, "Redox regulation of FoxO transcription factors," Redox Biology, vol. 6, pp. 51-72, 2015.

[144] Z. Tothova and D. G. Gilliland, "FoxO transcription factors and stem cell homeostasis: insights from the hematopoietic system," Cell Stem Cell, vol. 1, no. 2, pp. 140-152, 2007.

[145] S. Yalcin, X. Zhang, J. P. Luciano et al., "Foxo3 is essential for the regulation of ataxia telangiectasia mutated and oxidative stressmediated homeostasis of hematopoietic stem cells," The Journal of Biological Chemistry, vol. 283, no. 37, pp. 25692-25705, 2008.

[146] E. V. Knatko, S. H. Ibbotson, Y. Zhang et al., "Nrf2 activation protects against solar-simulated ultraviolet radiation in mice and humans," Cancer Prevention Research, vol. 8, no. 6, pp. 475486, 2015.

[147] L. Marrot, C. Jones, P. Perez, and J.-R. Meunier, “The significance of $\mathrm{Nrf} 2$ pathway in (photo)-oxidative stress response in melanocytes and keratinocytes of the human epidermis," Pigment Cell and Melanoma Research, vol. 21, no. 1, pp. 79-88, 2008. 
[148] M. Schafer and S. Werner, "Nrf2-A regulator of keratinocyte redox signaling," Free Radical Biology and Medicine, vol. 88, pp. 243-252, 2015.

[149] F. Gruber, H. Mayer, B. Lengauer et al., "NF-E2-related factor 2 regulates the stress response to UVA-1-oxidized phospholipids in skin cells," The FASEB Journal, vol. 24, no. 1, pp. 39-48, 2010.

[150] J. L. Zhong, G. P. Edwards, C. Raval, H. Li, and R. M. Tyrrell, "The role of Nrf2 in ultraviolet A mediated heme oxygenase 1 induction in human skin fibroblasts," Photochemical \& Photobiological Sciences, vol. 9, no. 1, pp. 18-24, 2010.

[151] A. L. Benedict, E. V. Knatko, and A. T. Dinkova-Kostova, "The indirect antioxidant sulforaphane protects against thiopurinemediated photooxidative stress," Carcinogenesis, vol. 33, no. 12, pp. 2457-2466, 2012.

[152] Y.-C. Hseu, C.-W. Chou, K. J. Senthil Kumar et al., "Ellagic acid protects human keratinocyte ( $\mathrm{HaCaT})$ cells against UVAinduced oxidative stress and apoptosis through the upregulation of the HO-1 and Nrf-2 antioxidant genes," Food and Chemical Toxicology, vol. 50, no. 5, pp. 1245-1255, 2012.

[153] S. Braun, C. Hanselmann, M. G. Gassmann et al., "Nrf2 transcription factor, a novel target of keratinocyte growth factor action which regulates gene expression and inflammation in the healing skin wound," Molecular and Cellular Biology, vol. 22, no. 15, pp. 5492-5505, 2002.

[154] M. Schäfer, S. Dütsch, U. auf dem Keller et al., "Nrf2 establishes a glutathione-mediated gradient of UVB cytoprotection in the epidermis," Genes \& Development, vol. 24, no. 10, pp. 1045-1058, 2010.

[155] W. Stahl and H. Sies, " $\beta$-carotene and other carotenoids in protection from sunlight," The American Journal of Clinical Nutrition, vol. 96, no. 5, pp. 1179S-1184S, 2012.

[156] F. Lieder, F. Reisen, T. Geppert et al., "Identification of UVprotective activators of nuclear factor erythroid-derived 2related factor 2 (Nrf2) by combining a chemical library screen with computer-based virtual screening," Journal of Biological Chemistry, vol. 287, no. 39, pp. 33001-33013, 2012.

[157] S. Tao, R. Justiniano, D. D. Zhang, and G. T. Wondrak, “The Nrf2-inducers tanshinone I and dihydrotanshinone protect human skin cells and reconstructed human skin against solar simulated UV," Redox Biology, vol. 1, no. 1, pp. 532-541, 2013.

[158] K. J. Rodriguez, H.-K. Wong, T. Oddos, M. Southall, B. Frei, and S. Kaur, "A purified feverfew extract protects from oxidative damage by inducing DNA repair in skin cells via a PI3-kinasedependent Nrf2/ARE pathway," Journal of Dermatological Science, vol. 72, no. 3, pp. 304-310, 2013.

[159] J. Jang, B.-R. Ye, S.-J. Heo et al., "Photo-oxidative stress by ultraviolet- $\mathrm{B}$ radiation and antioxidative defense of eckstolonol in human keratinocytes," Environmental Toxicology and Pharmacology, vol. 34, no. 3, pp. 926-934, 2012.

[160] S.-Z. Kong, H.-M. Chen, X.-T. Yu et al., “The protective effect of $18 \beta$-Glycyrrhetinic acid against UV irradiation induced photoaging in mice," Experimental Gerontology, vol. 61, pp. 147155, 2015.

[161] E. Rodríguez-Yanes, J. Cuevas, S. González, and J. Mallol, "Oral administration of Polypodium leucotomos delays skin tumor development and increases epidermal p53 expression and the anti-oxidant status of UV-irradiated hairless mice," Experimental Dermatology, vol. 23, no. 7, pp. 526-528, 2014.

[162] J.-E. Park, H.-B. Pyun, S. W. Woo, J.-H. Jeong, and J.-K. Hwang, "The protective effect of kaempferia parviflora extract on UVBinduced skin photoaging in hairless mice," Photodermatology
Photoimmunology and Photomedicine, vol. 30, no. 5, pp. 237245, 2014.

[163] W. Thangboonjit, S. Limsaeng-u-rai, T. Pluemsamran, and U. Panich, "Comparative evaluation of antityrosinase and antioxidant activities of dietary phenolics and their activities in melanoma cells exposed to UVA," Siriraj Medicine Journal, vol. 66, no. 1, pp. 5-10, 2014.

[164] T. Pluemsamran, T. Onkoksoong, and U. Panich, "Caffeic acid and ferulic acid inhibit UVA-induced matrix metalloproteinase-1 through regulation of antioxidant defense system in keratinocyte HaCaT cells," Photochemistry and Photobiology, vol. 88, no. 4, pp. 961-968, 2012.

[165] U. Panich, T. Onkoksoong, S. Limsaengurai, P. Akarasereenont, and A. Wongkajornsilp, "UVA-induced melanogenesis and modulation of glutathione redox system in different melanoma cell lines: the protective effect of gallic acid," Journal of Photochemistry and Photobiology B: Biology, vol. 108, pp. 16-22, 2012.

[166] A. Chaiprasongsuk, T. Onkoksoong, T. Pluemsamran, S. Limsaengurai, and U. Panich, "Photoprotection by dietary phenolics against melanogenesis induced by UVA through Nrf2dependent antioxidant responses," Redox Biology, vol. 8, pp. 7990, 2016.

[167] H.-R. Choi, Y.-A. Kang, J.-W. Shin, J.-I. Na, C.-H. Huh, and K.-C. Park, "Redox status is critical for stemness in skin equivalents," Oxidative Medicine and Cellular Longevity, vol. 2012, Article ID 819623, 7 pages, 2012.

[168] H.-R. Choi, J.-W. Shin, J.-I. Na, K.-M. Nam, H.-S. Lee, and K.-C. Park, "Novel antioxidant tripeptide 'ACQ' can prevent UV-induced cell death and preserve the number of epidermal stem cells," Oxidative Medicine and Cellular Longevity, vol. 2015, Article ID 359740, 11 pages, 2015.

[169] W.-S. Kim, B.-S. Park, and J.-H. Sung, "The wound-healing and antioxidant effects of adipose-derived stem cells," Expert Opinion on Biological Therapy, vol. 9, no. 7, pp. 879-887, 2009. 

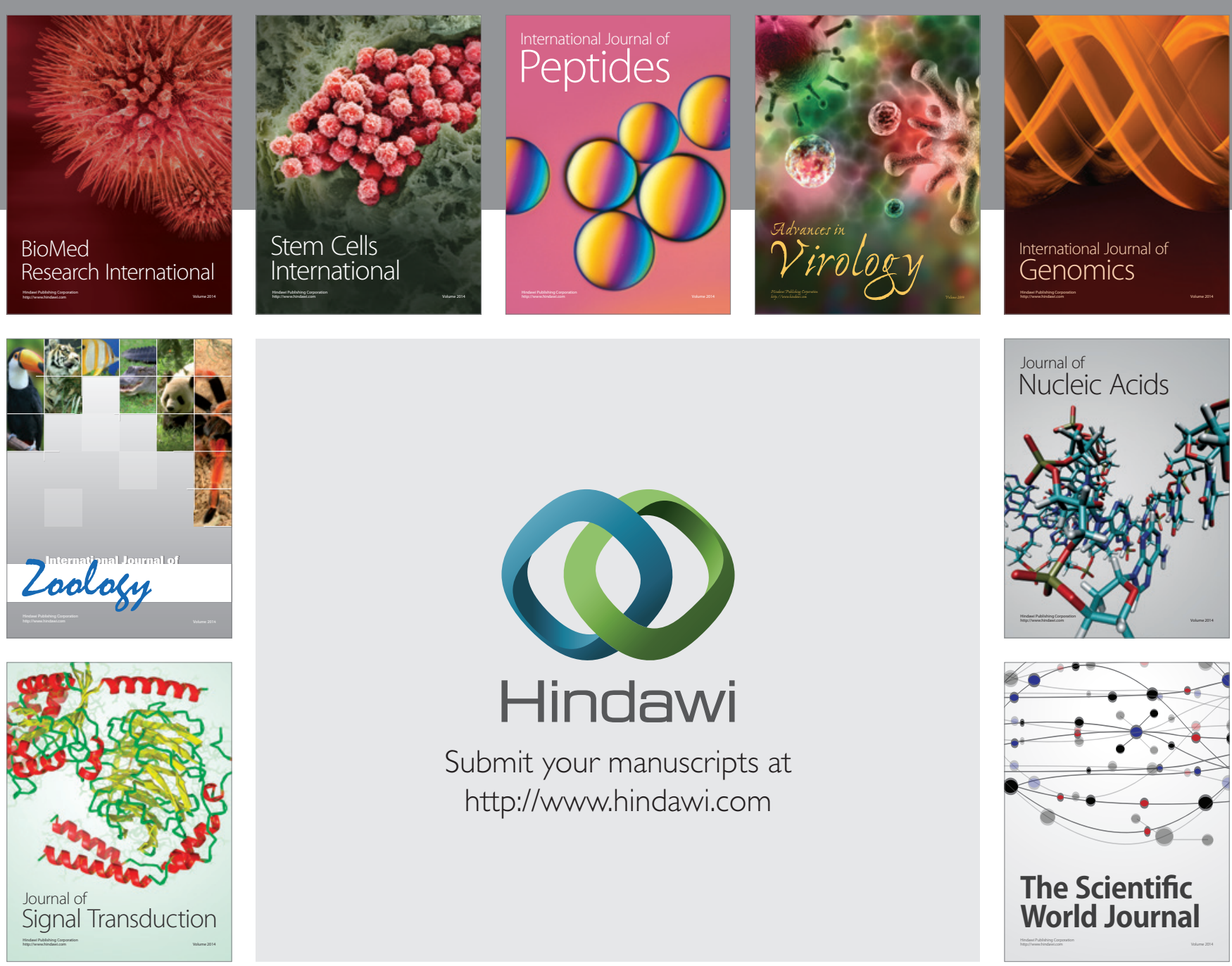

Submit your manuscripts at

http://www.hindawi.com
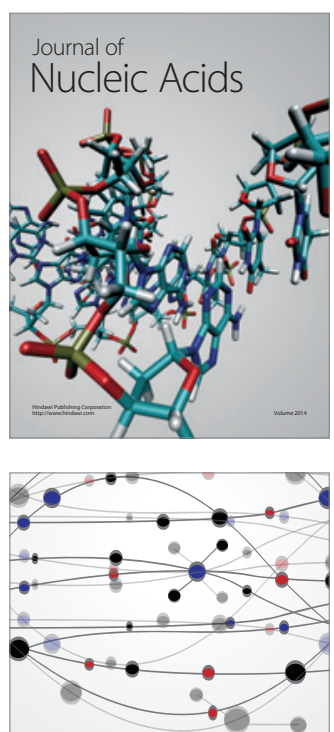

The Scientific World Journal
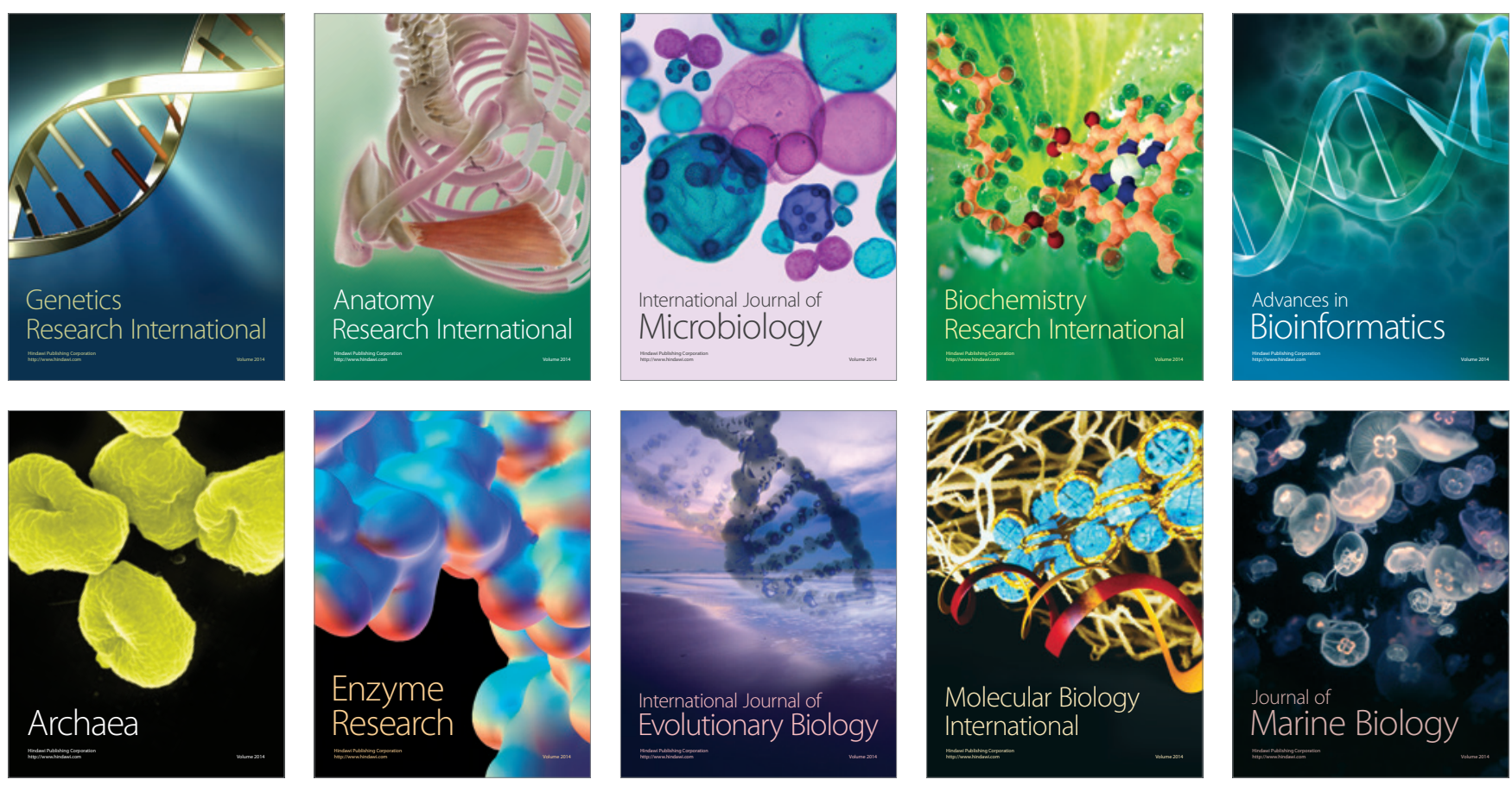